\title{
Research Paper: The Effectiveness of Nonviolent Communication Program Training on Mother-Child Interaction in Mothers of Children With Intellectual Disability
}

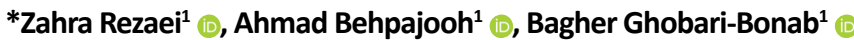

1. Department of Psychology \& Education of Exceptional Children, Faculty of Psychology and Education, University of Tehran, Tehran, Iran.

\begin{tabular}{|c|c|}
\hline $\begin{array}{l}\text { Use your devicect tossan } \\
\text { and read the article online }\end{array}$ & Citation Rezaei Z, Behpajooh A, Ghobari-Bonab B. [The Effectiveness of Nonviolent Communication Program Training \\
\hline 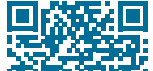 & $\begin{array}{l}\text { on Mother-Child Interaction in Mothers of Children With Intellectual Disability (Persian)]. Archives of Rehabilitation. 2019; } \\
\text { 20(1):40-51. http://dx.doi.org/10.32598/rj.20.1.40 }\end{array}$ \\
\hline 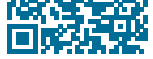 & doli http://dx.doi.org/10.32598/rj.20.1.40 \\
\hline
\end{tabular}

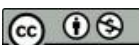

Received: 02 Oct 2018

Accepted: 25 Jan 2019

Available Online: 01 Apr 2019

\section{ABSTRACT}

Objective Besides their communication and socialization problems, many children with Intellectual Disability (ID) have difficulties with their parents, siblings, and teachers. The enduring nature of social reactions easily leads to social isolation. Thus, many children and adults with ID have few friends, even though they may desperately want to be liked. This can set up a vicious circle in which they attempt to win friends by latching onto the least chance for interaction with others. Regarding the characteristics of nonviolent communication program training, it seems that this program could reduce communication problems and improve mother-child interaction of children with ID. The nonviolent communication training program is one method for improvement of communication skills in parents of the children with ID because these parents are often facing problem in communication with their children. Nowadays, much effort is made for improving mother-child interaction, especially in mothers of children with ID. Therefore, the purpose of the present study was to investigate the effect of nonviolent communication program training on mother-child interaction in mothers of children with ID.

Materials \& Methods The present research was a quasi-experimental study with pretest-posttest and a control group. The study population included all of the mothers of children with ID who attend to Alborz Educational and Rehabilitation Institute which is located in Alborz Province, Iran under the supervision of welfare organization. The study sample included 30 mothers selected by convenience sampling method and assigned to two groups. The experimental group participated in a communication skills training program based on life language for 8 sessions (90 minutes for per session; twice a week), while the control group received no such training. The study instrument was the Pianta mother-child interaction scale (1992). The Pianta mother-child interaction scale was completed by mothers for all subjects in pretest and posttest. The study data were collected through the questionnaire before and after the training sessions. Multivariate analysis of covariance was performed in SPSS (Version 22) for analyzing the obtained data.

Results First, the normality of study variables and contingency of variance and covariance assumptions were tested. The Kolmogorov-Smirnov test showed that all variables were normally distributed $(P>0.05)$. Also, the Box test confirmed the contingency of variance-covariance assumption. So, assumptions of the MANCOVA test were confirmed and MANCOVA test can be used for analysis of data. The results of MANCOVA revealed that posttest scores of experimental and control groups had a significant difference with regard to mother-child interaction $(P<0.001)$. Also, the results of MANCOVA revealed that posttest scores of experimental and control groups had a significant difference with regard to conflict, closeness, and dependency subscales $(P<0.001)$. It can be stated that

\section{* Corresponding Author:}

Zahra Rezaei, MSc.

Address: Department of Psychology \& Education of Exceptional Children, Faculty of Psychology and Education, University of Tehran, Tehran, Iran Tel: +98 (28) 32225179

E-Mail: z.rezaei2561@gmail.com 
Keywords:

Nonviolent communication, Mother-child interaction, Intellectual disability according to $\mathrm{Eta}^{2}, 67 \%$ of the variance in mother-child interaction can be explained by the subjects participation in the nonviolent communication training program. Also, according to $\mathrm{Eta}^{2}$, respectively $63 \%, 65 \%$, and $66 \%$ of the variance in components of conflict, closeness, and dependency can be explained by the subjects' participation in the nonviolent communication training program. Therefore, communication skills training based on life language has a positive effect on motherchild interaction of the mothers of children with ID.

Conclusion Parents of children with ID has more problems in communication with their children than parents of any other kind of exceptional children. It doesn't take long that these children be ostracized from social activities. Unfortunately, the negative social status experienced by children with ID is difficult to overcome and usually long-lasting. Nonviolent communication program training improves mother-child interaction in mothers of children with ID. Therefore, providing nonviolent communication program training has particular importance for these mothers. 
This Page Intentionally Left Blank 


\title{
اثربخشى آموزش برنامه ارتباط بدون خشونت بر تعامل مادركودك در مادران با كودك كمتوان ذهنى
}

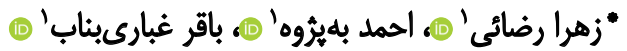

1- كروه روانشناسى و آموزش كودكان استثنايي، دانشكده روانشناسى و علوم تربيتى، دانشكاه تهران، تهرانء ايران.

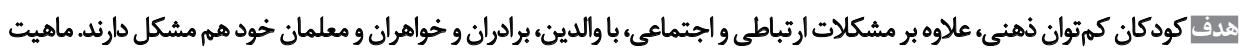

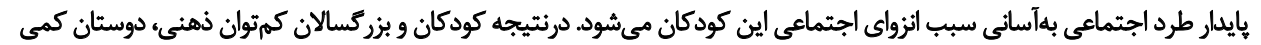

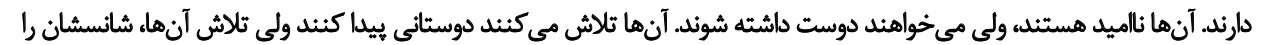

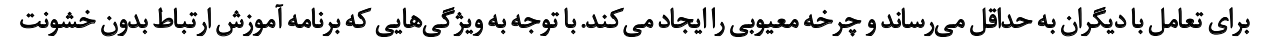

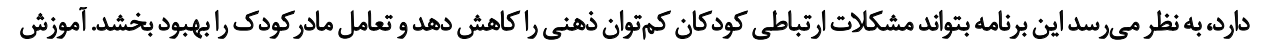

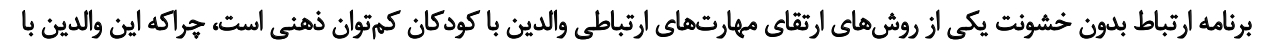

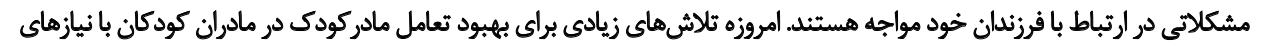

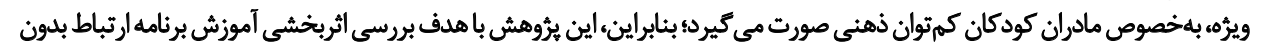

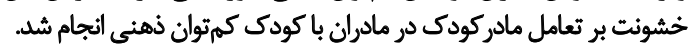

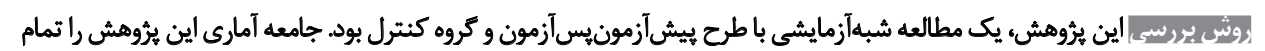

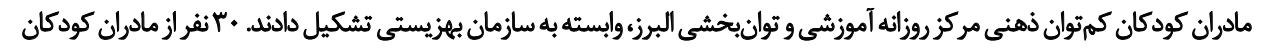

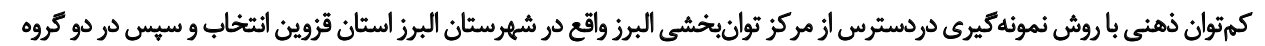

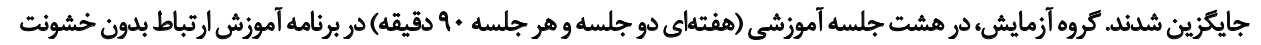

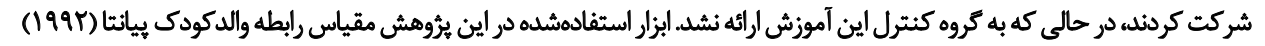

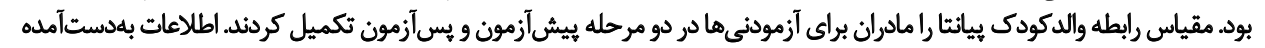

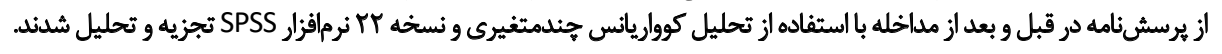

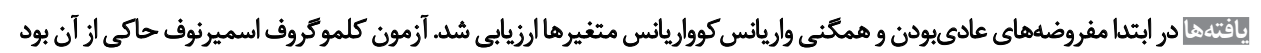

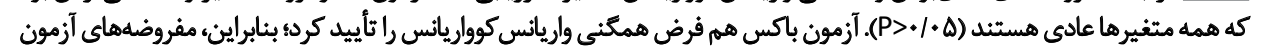

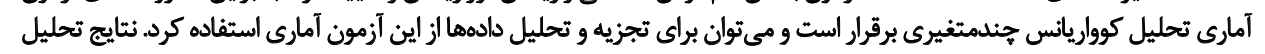

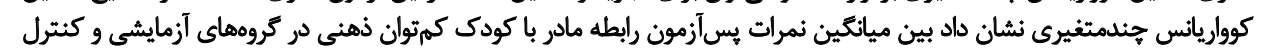

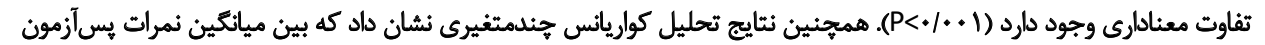

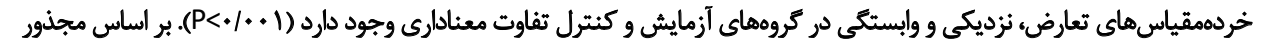

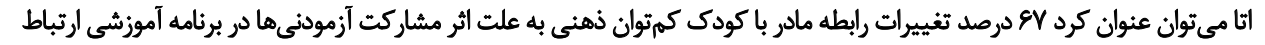

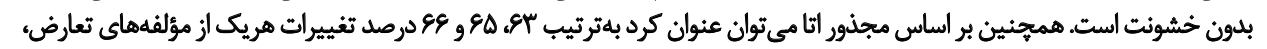

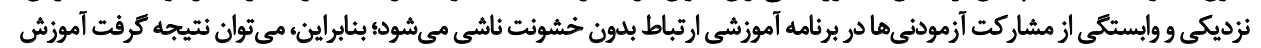

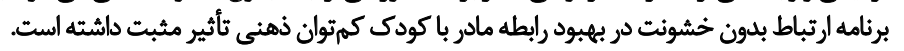

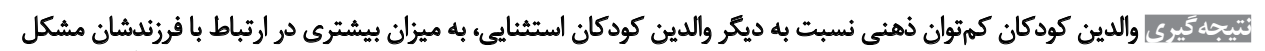

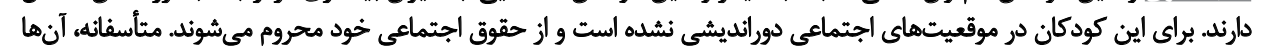

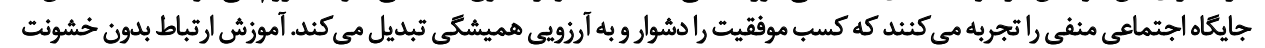

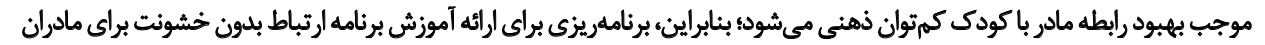
باكودك كمتوان ذهنى اهميت ويرماي دارد.
\end{abstract} تاريخ انتشار: rا فروردين

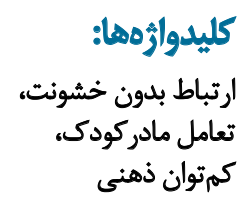

كمتوان ذهنى 
افراد كمك مي كنند تا در ييامهايي كه به صورت نمادين به شخص

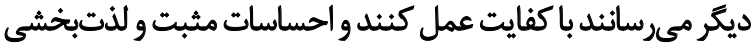

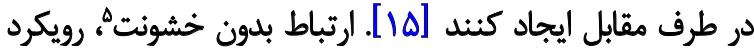

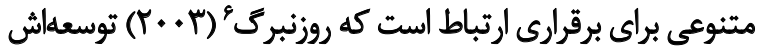

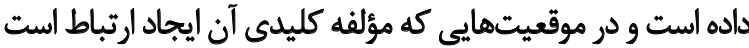

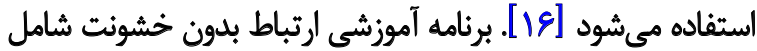

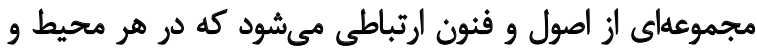

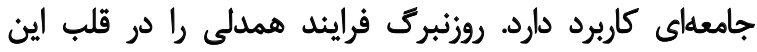

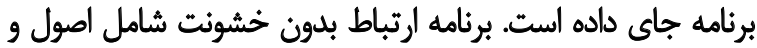

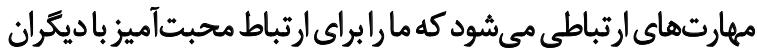

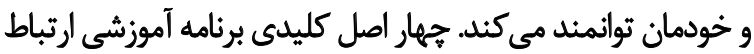

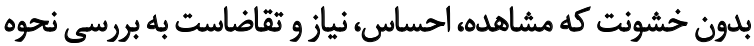

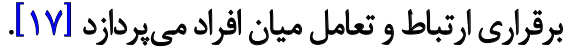

اين برنامه كه شامل جهار اصل كليدى مشاهده، احساس، نياز و

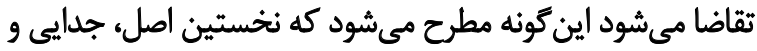

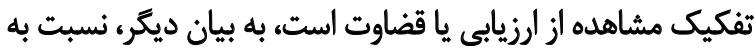

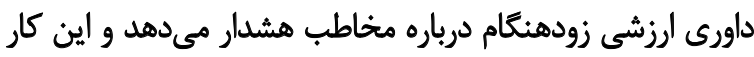

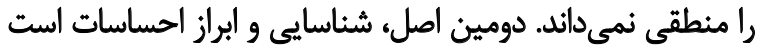

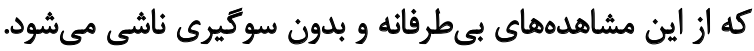
سومين اصل، مسئوليت يذيرى براى احساسات نام نام دارد و وآموزش مىدهد كه افراد نسبت به احساسات و عواطف خول خود و و ديكران

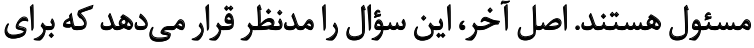

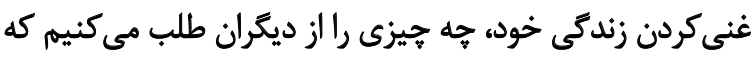

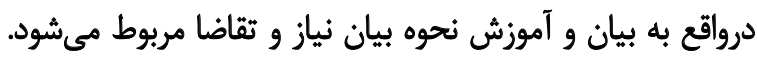

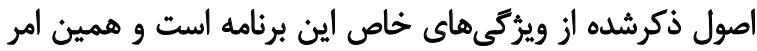

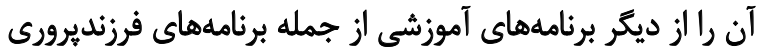

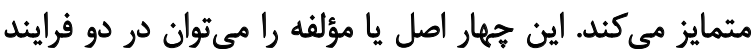

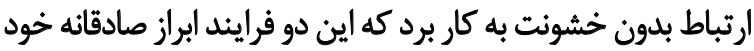

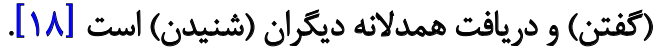

يُروهشهاى مختلفى در حوزه اثربخشى آموزش برنامه ارتباط

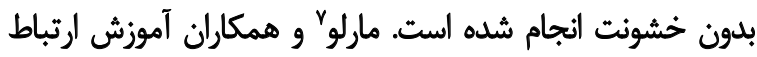

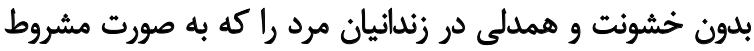

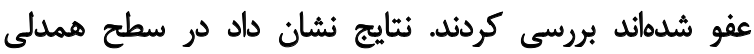

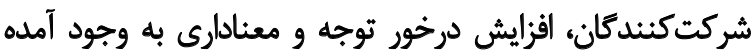

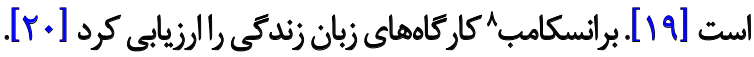

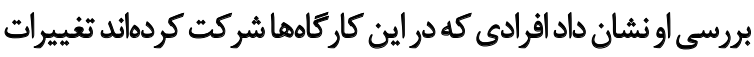

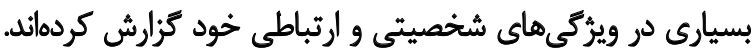

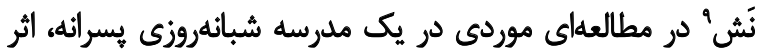
آموزش ارتباط بدون خشونت در حل و فصل مناقشات رابر بررسى كرد برد

5. Nonviolent Communication (NVC)

6. Rosenberg

7. Marlow

8. Branscomb

9. Nash
مقلمه

يكى از عوامل مهم در ايجاد و كسترش تسهيلات آموزش و و

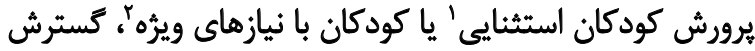

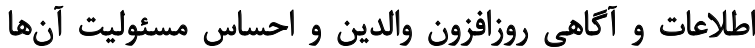

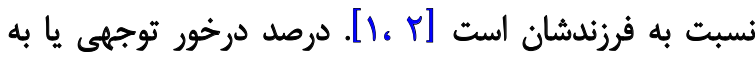

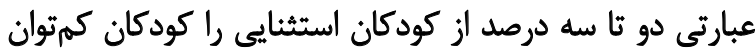

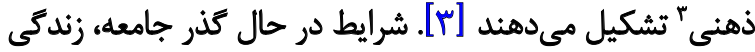

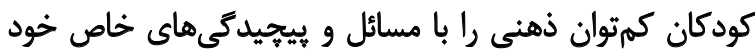

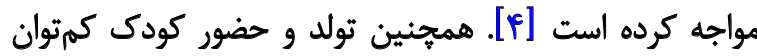

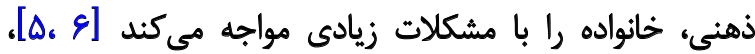

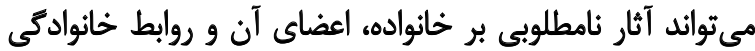

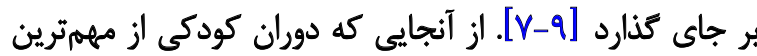

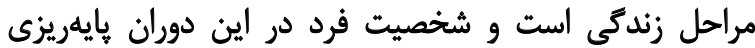

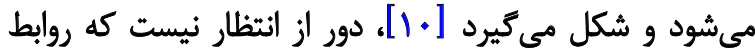

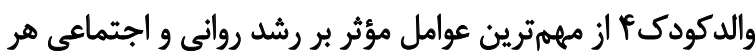

كودكى محسوب شود [11] [11].

روابط والدكودى به ياسخهاى هيجانى و رفتارى متقابل بين

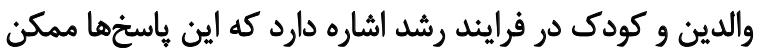

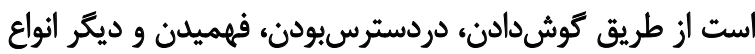

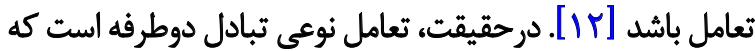

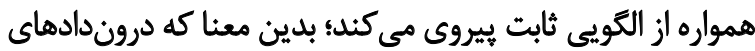

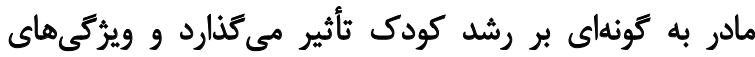

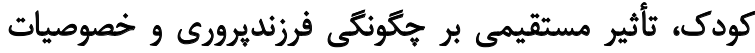

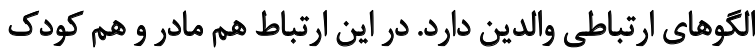

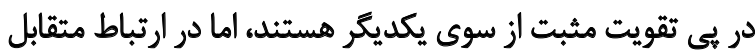

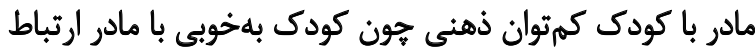

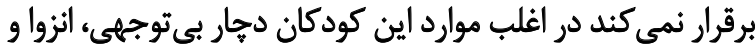

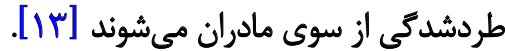

درحقيقت مراقبت عاطفى مادر از كودك موقعيتى را فراهم مى كئد

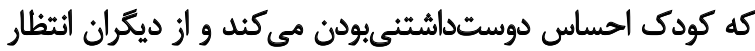

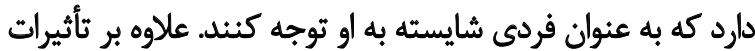

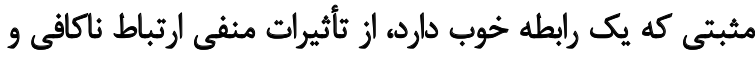

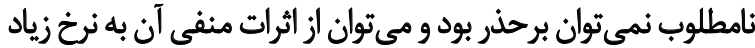

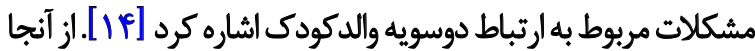

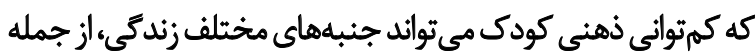

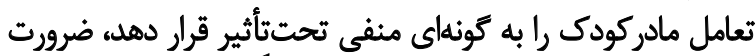

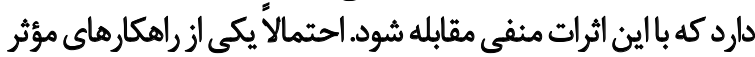

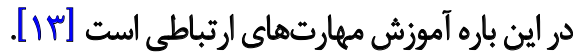

مهارتهاى ارتباطى نوعى توانايىهاي اختصاصى هستند كه به

1. Exceptional children

2. Children with special needs

3. Children with intellectual disability

4. Parent-child interaction 
با توجه به بررسىهاى انجامشده در زمينه برنامه آموزش ارتباط

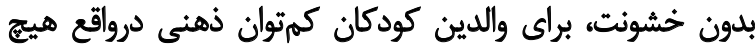

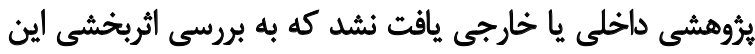

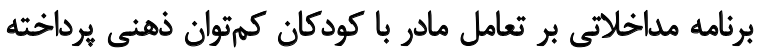

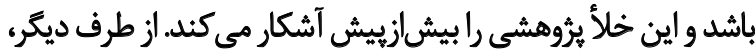

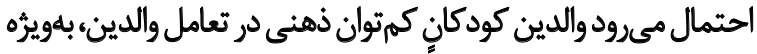

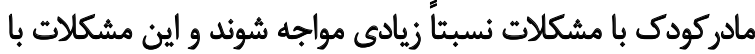

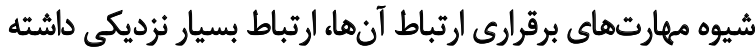

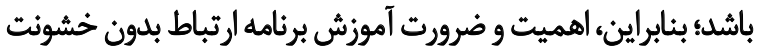

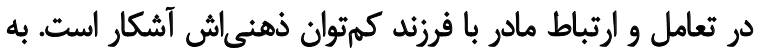

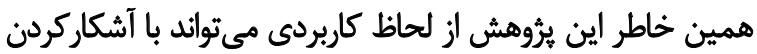

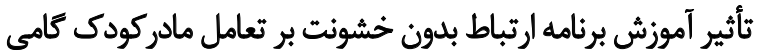

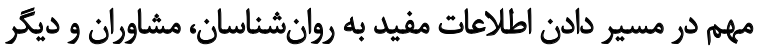

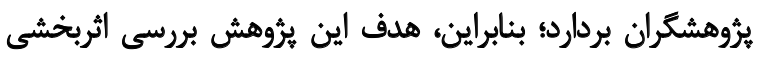

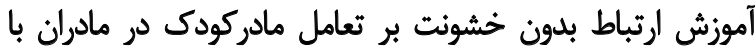
كودكان كمتروان ذهنى است.

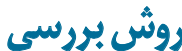

اين بُروهش، مطالعهاى شبهآزمايشى باطرح ييش آزمونيس آزمون

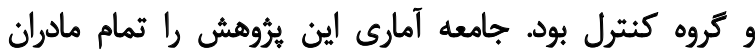

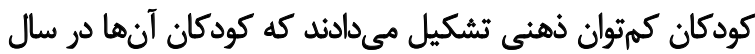

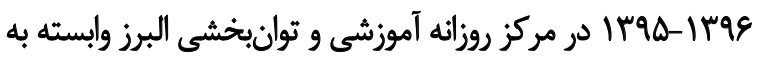

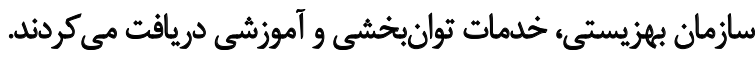

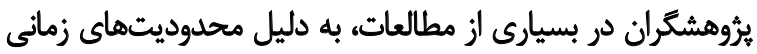

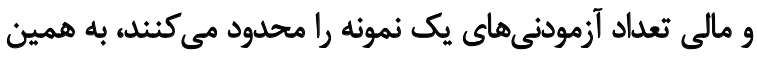

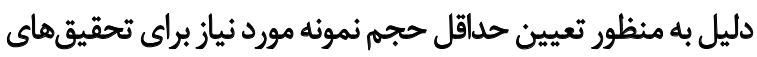

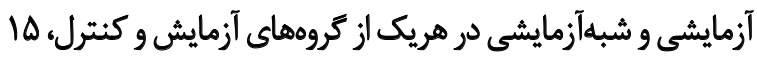

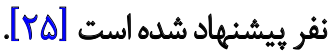

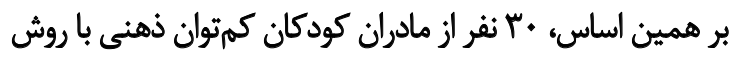

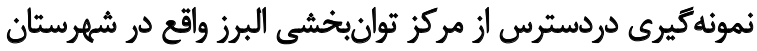

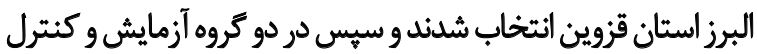

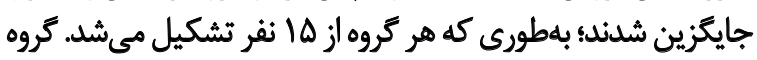

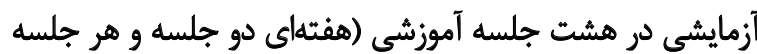

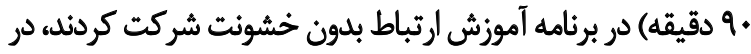

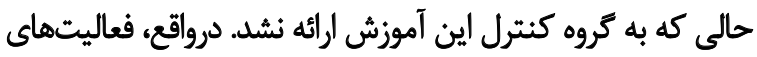

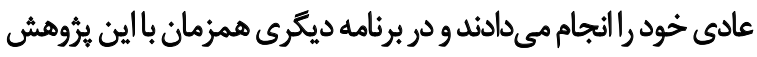

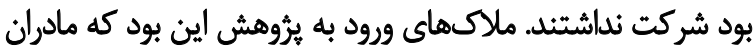

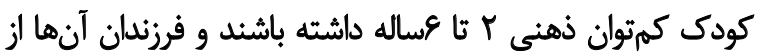

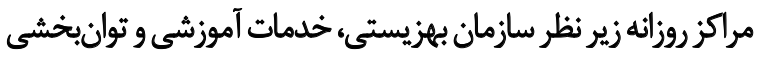

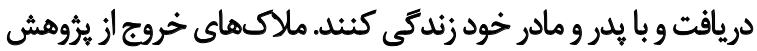

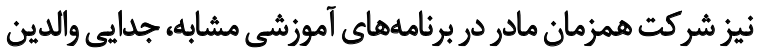

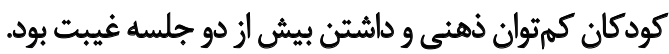

و ونتايج نشان داد آموزش برنامه ارتباط بدون خشونت تأثير معنادارى

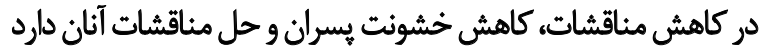

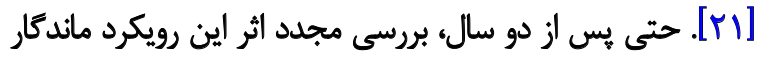

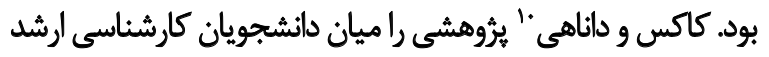

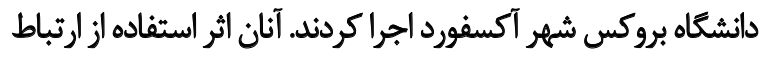

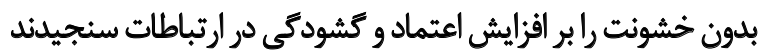

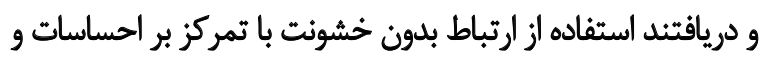

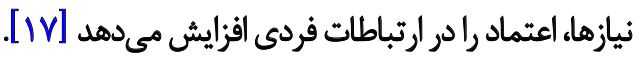

در اين بُؤهش ارتباط دانشجويان به صورت آنلاين بود و تعامل

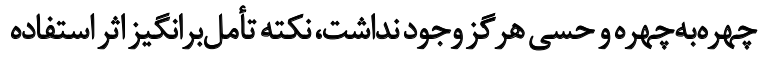

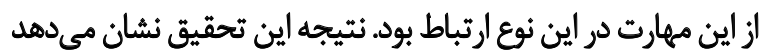

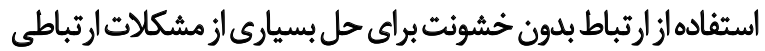

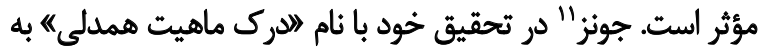

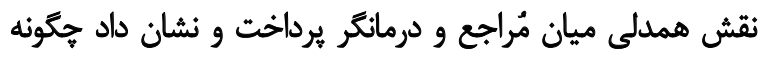

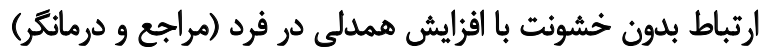

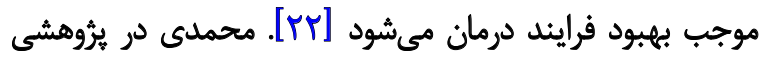

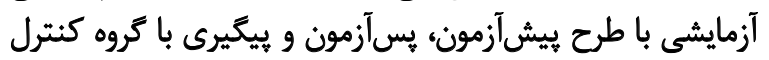

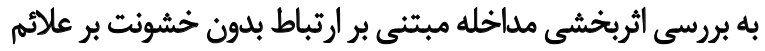

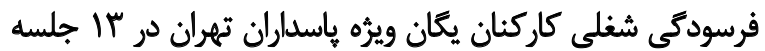

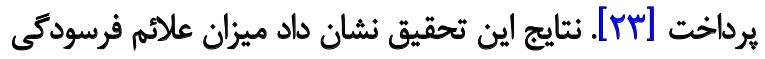

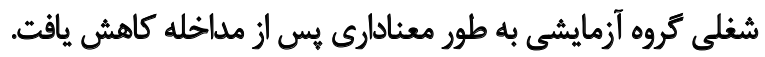

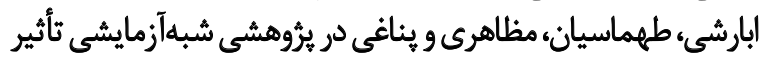

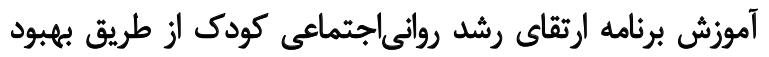

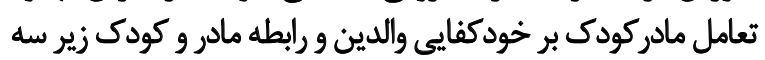

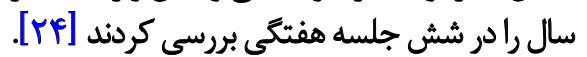

نتايج اين يُوهش حاكى از آن بود كه برنامه ارتقاى رشد

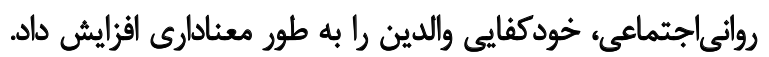

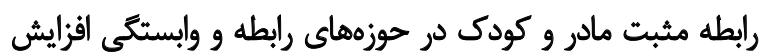

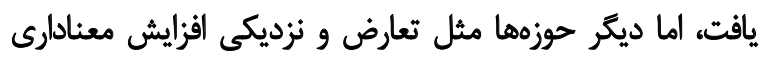

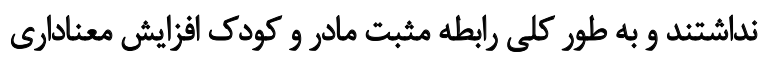

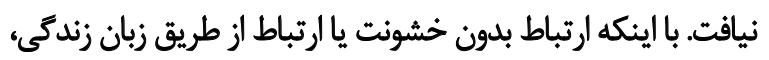

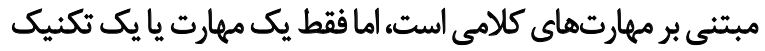

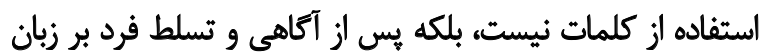

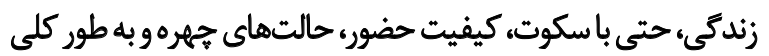

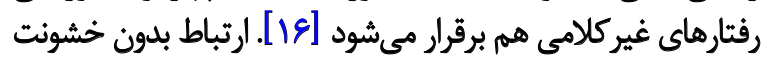

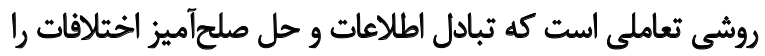

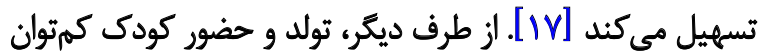

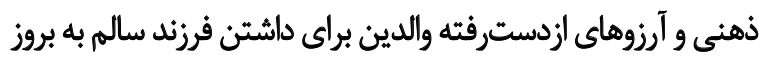

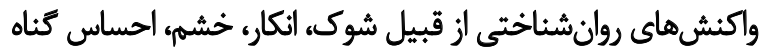

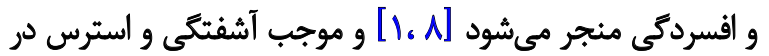

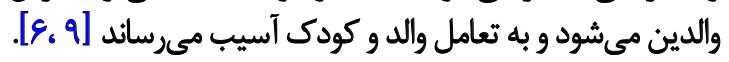


جدول ا. محتواي جلسات برنامه آموزشى ارتباط بدون خشونت

\begin{tabular}{|c|c|c|c|c|}
\hline تكاليف خاته & تكاليف و فعاليتها & محتواي جلسات & هدف & 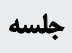 \\
\hline مطالعه درباره ويزّكى ذهاى كودكان كمتوان & ارزيابى مهارتهاى ارتباطى، از طريق و بحثى & 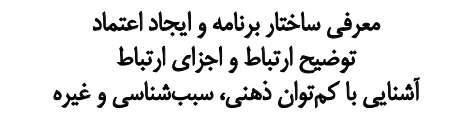 & 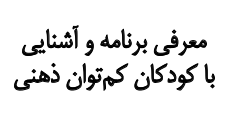 & 1 \\
\hline شناساييى موانع برقرارى ارتباطا در جمع & بحث كروهى، يرسش و ياسخ و بازى & 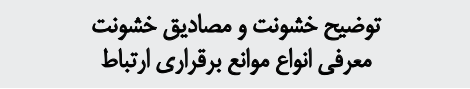 & ارتباه بيكانهساز از زئ & $r$ \\
\hline 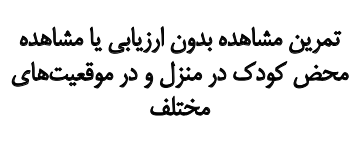 & 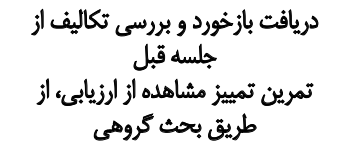 & 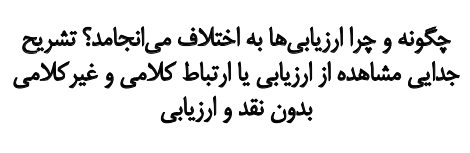 & 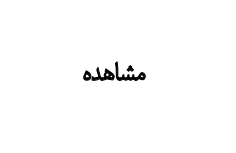 & $r$ \\
\hline 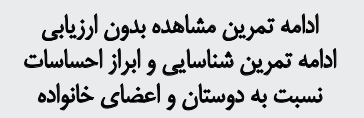 & تمرين تمييز احساسات از افكار و نقاشيى مرئه & 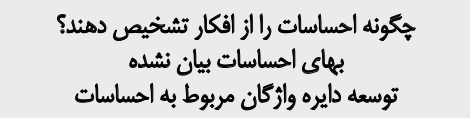 & شناساسي و ابراز & r \\
\hline 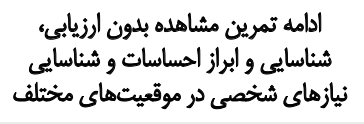 & ششفافسازى أبراز نيازها از طريق داستان & 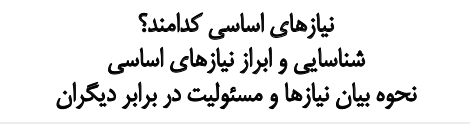 & احساستات خونيدى & $\Delta$ \\
\hline تمرين تقاضاى منطقى در موقعيتهاى & تمرين تمييز تقاضا الز درخواست آمرانه & 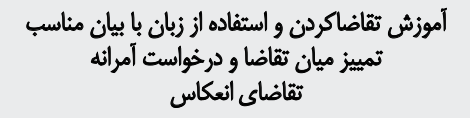 & البراز تقاضا & 8 \\
\hline \multirow[t]{2}{*}{ 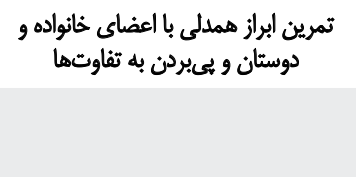 } & 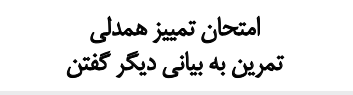 & 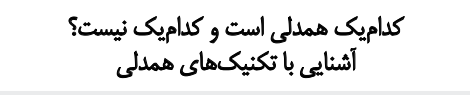 & دريافت همدلاته & $\gamma$ \\
\hline & درياقت بازخورد ازئ جلسات قبل و & مرور تمرينهاى خانكى & ت تكرار وخلاصه & A \\
\hline
\end{tabular}

نكات اخلاقى يُروهش، اهميت، ضرورت و اهداف اين يُروهش در

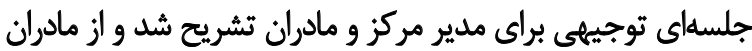

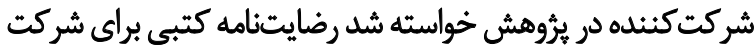

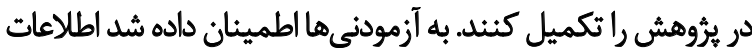

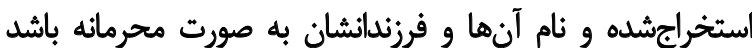

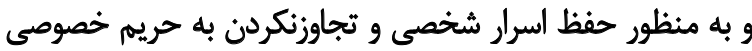

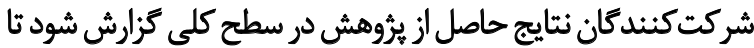

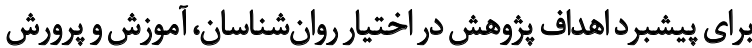

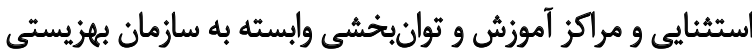

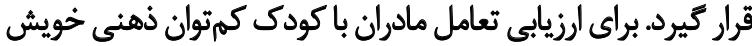

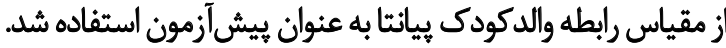

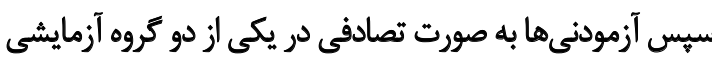

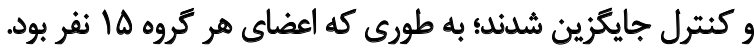

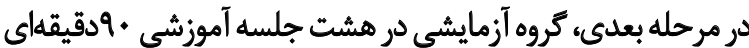

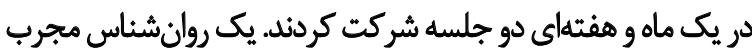

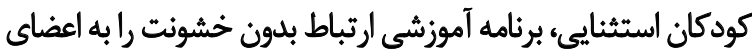

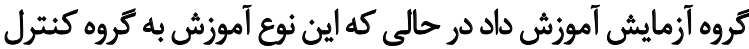

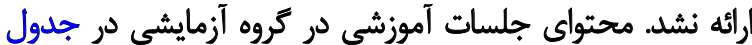
شماره إمده است.

در آخرين مرحله يُروهش، هر دو تروه با مقياس رابطه والدكودى
براى جمعآورى اطلاعات از مقياس رابطه والدكودى يُانتا؟"

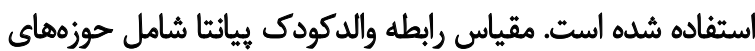

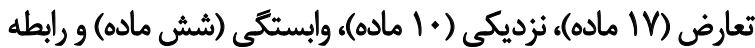

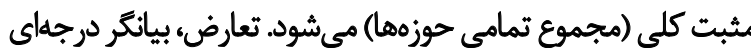

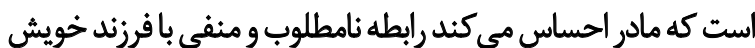

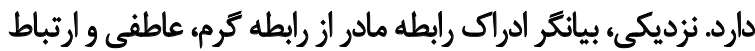

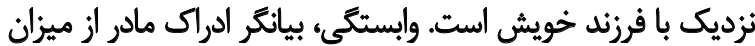

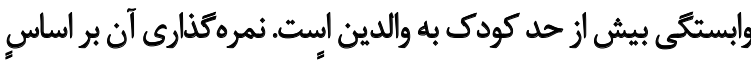

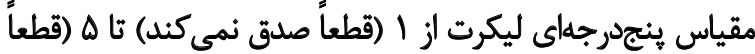

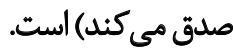

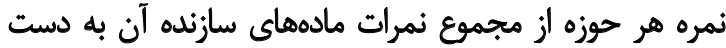

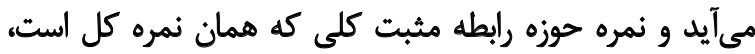

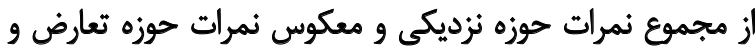

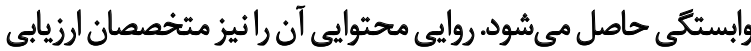

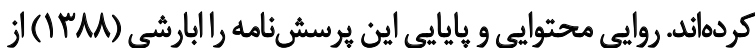

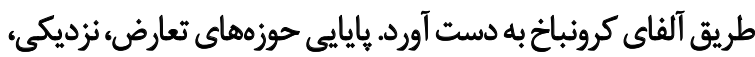

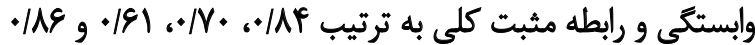

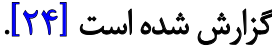
در اولين مرحله يُروهش يس از انتخاب آزمودنىها، به دليل رعايت

12. Parent child relationship scale or PCRS of Piyanta 
براى تعيين هعنادارى همبستكى كافي بين متغيرهاي وابسته.

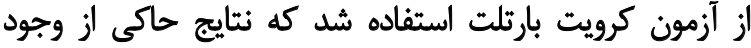

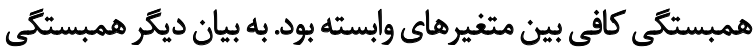

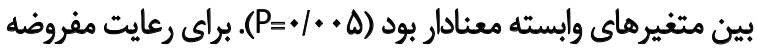

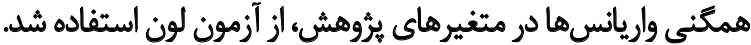

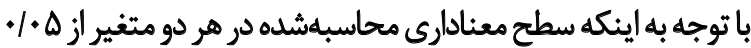

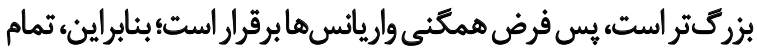

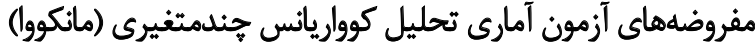

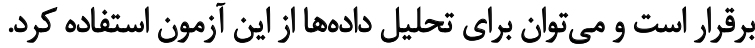

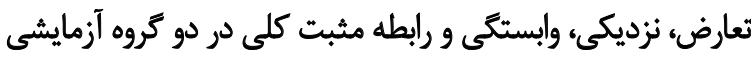

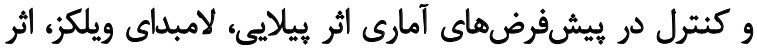

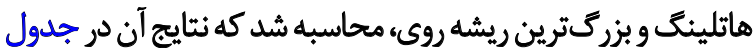
شماره بارائه شده است

نتايج آزمونهاي جهاركانه كه در جدول شماره ب آمده است، حاكي از آن است كه كروه آزمايشي و كنئه

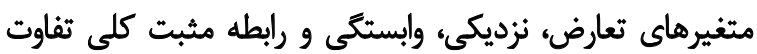

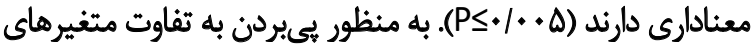

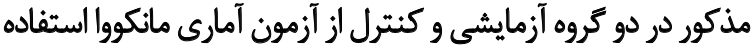

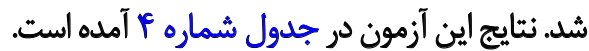
در اين تحليل، متغير ييشآزمون به دليل همبستيكي با يسآزمهون

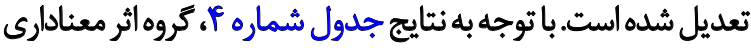

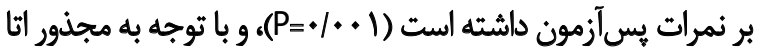

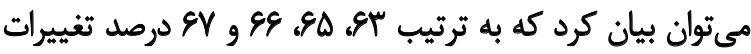

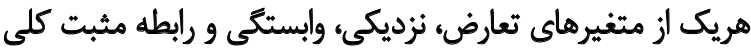

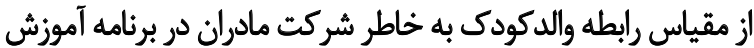

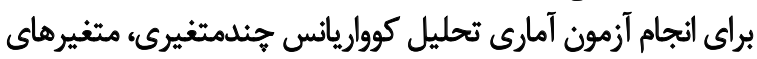

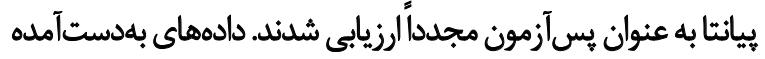

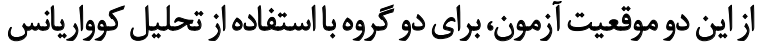

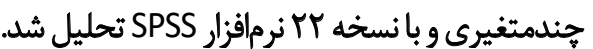

Lation

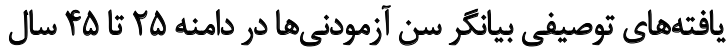

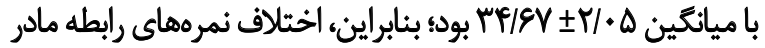

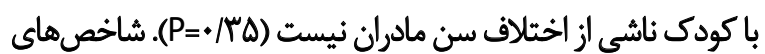

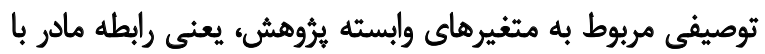

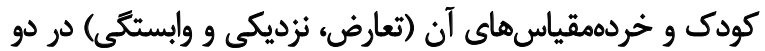

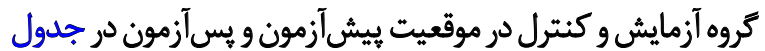

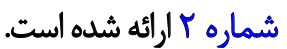

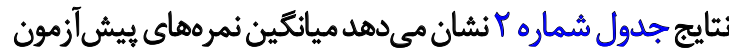

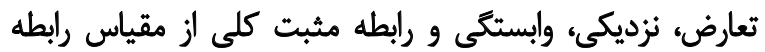

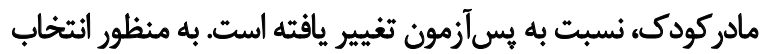

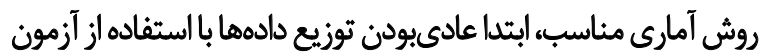

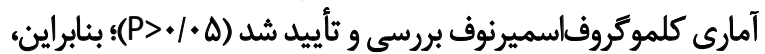

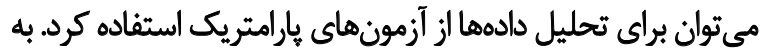

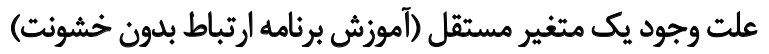

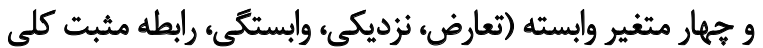

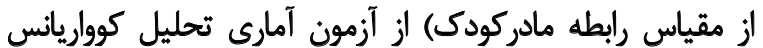

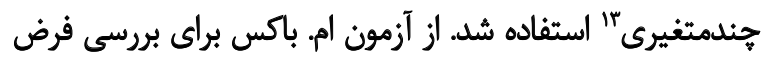

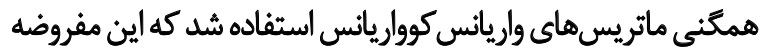

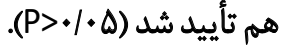

7. MANCOVA

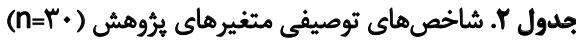

\begin{tabular}{|c|c|c|c|c|c|c|c|c|}
\hline \multicolumn{6}{|c|}{ كروهها } & \multirow{3}{*}{ موقعيت } & \multirow{3}{*}{ مثغيرها } & \\
\hline \multicolumn{3}{|c|}{ كثترل } & \multicolumn{3}{|c|}{ أزمايش } & & & \\
\hline ثرماليتى & انحراف معيار & مياتكين & نرماليتى & افحراف معيار & مياكين & & & \\
\hline+191 & $r / A r$ & $\Delta F / T$. &.$/ \Delta F$ & V/FO & $\Delta F / \Delta H$ & ييشأزمون & & \\
\hline.$/ \pi t$ & $T / M$ & $\Delta F / F$ &.$/ 49$ & $\mathbb{1} / \%$ & PV/N & يس آزمون & تعارض & \\
\hline.$/ \Delta V$ & $V / \Delta \Delta$ & $r+1 \Delta r$ & 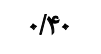 & VED & IVA. & ييش أزمون & & \\
\hline - IAT & $1 / \pi$ & $r \cdot / N$ &.$/ \pi$ & .198 & $r \Delta / M^{\prime}$ & يس أزمون & & $\begin{array}{l}\frac{3}{3} \\
\frac{3}{3}\end{array}$ \\
\hline.$/ 4$ &.$/ N$ & War & $.10 \mathrm{~A}$ & - Ma & $19 \cdot 8$ & ييش آزمون & وابستكي & yे \\
\hline$\cdot / N$ &.$/ 91$ & WE. &. & 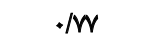 & $10 / \%$ & يس آزمون & & \\
\hline$\cdot \mathbb{N}$ & $T / 18$ & espes &.$/ T O$ & r/AT & $8 \& 1.0$ & ييشأزمون & $15=0$ & \\
\hline.$M$ & $r / 89$ & expes & r & $T / T \Delta$ & Nor & يسأزمون & 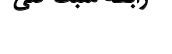 & \\
\hline
\end{tabular}


جدول "ا. نتايج كلى تحليل كوواريانس جندمتغيرى براى رابطه والدكودى

\begin{tabular}{|c|c|c|c|c|c|}
\hline سطح معنادارى & $\mathbf{F}$ & درجه آزادى خطا & درجه آزادى فرضيه & مقدار & ثام آزمون \\
\hline$\leq+1 * \bullet$ & $1981 / 94$ & rr & r &.$/ 99$ & اثر بييلايى \\
\hline$\leq+1 * \Delta$ & IEI/AT & rr & r & $. *+r$ & لامبداي ويلكز \\
\hline$\leqq * 1 \cdots \Delta$ & IEI/A & r & f & $P|Q / T|$ & أثر هاتلينك \\
\hline$\leq \odot / \bullet \bullet$ & $1891 / 9$ & rr & r & $F \mid \Delta / / F$ & بزركترين ريشهروى \\
\hline
\end{tabular}

توانبخننى

جدول †. نتايج تفكيكى تحليل كوواريانس جندمتغيرى براى متغيرهاى رابطه والدكودى

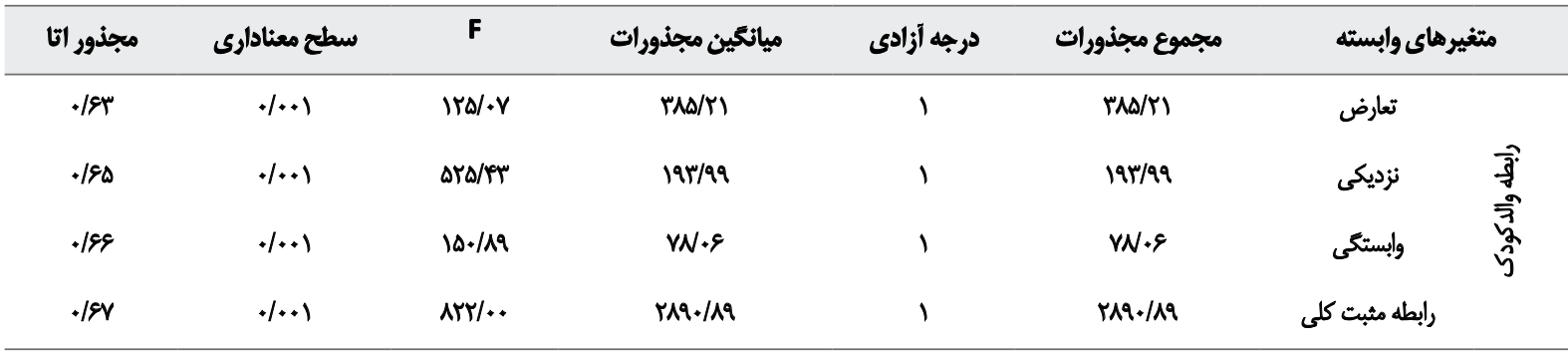

توانبخننى

داوطلبانه از مادرانى كه كودكان خود را به مهدكودك مى فئرستادند ارتباط بدون خُشونت است.

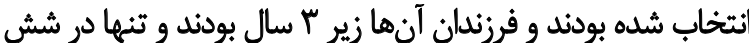

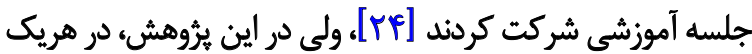

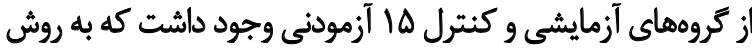

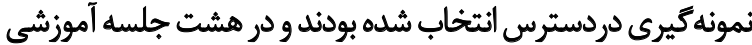

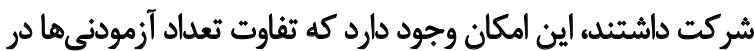

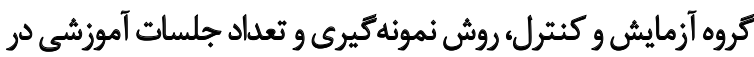

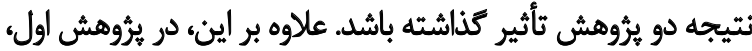

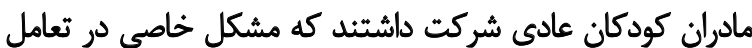

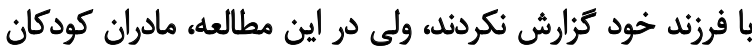

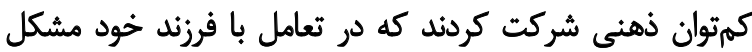

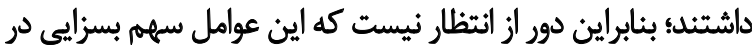
متناقضبودن نتايج اين دو مطالعه داشته باشد.

براى تبيين يافتههاى همسو با يافته اخير مى توان كفت كه حضور

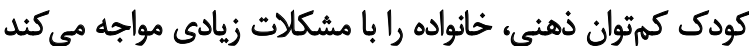

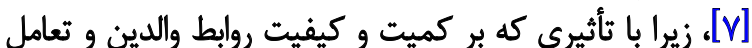

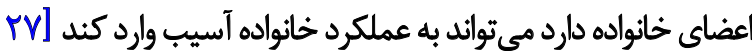

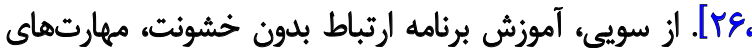

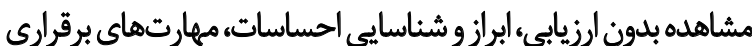

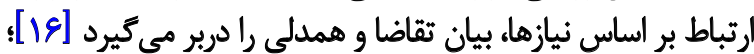

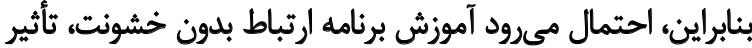

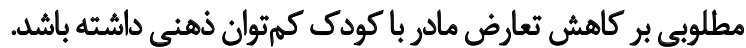
دومين يافته يُوهش مبنى بر اين بود كه آموزش برنامه ارتباط بردياط

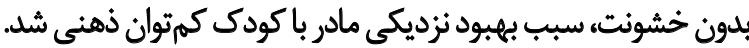

اين يثوهش باهدف بررسى اثربخشى آموزش ارتباط بدون خشونت

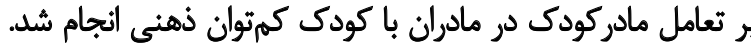

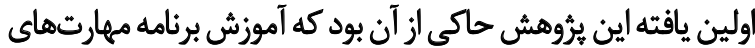

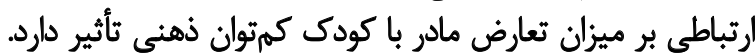

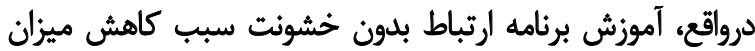

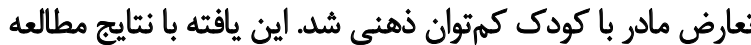

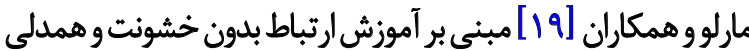

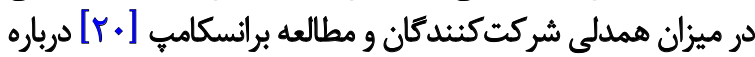

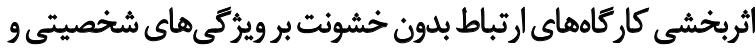

$$
\text { ارتباطى آزمودنى ها همسو بوداي. }
$$

همجنين با نتايج يُروهش كاكس و داناهى مبنى بر تأثير آموزش بردي

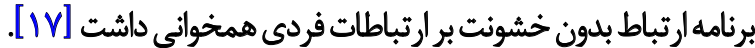

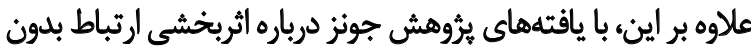

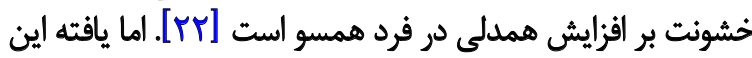

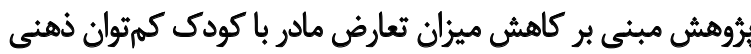

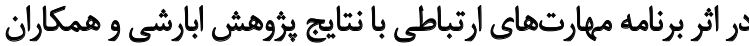

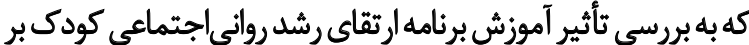

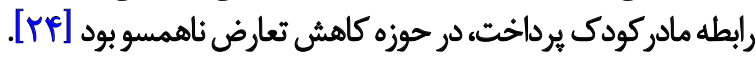

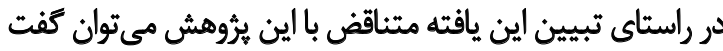

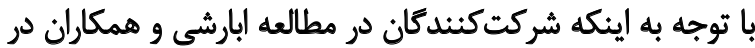

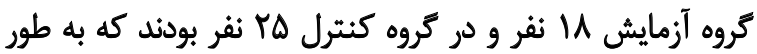


آخرين يافتهّه برؤهش مبنى بر اين بود كه آموزش برنامه ارتباط

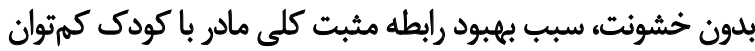

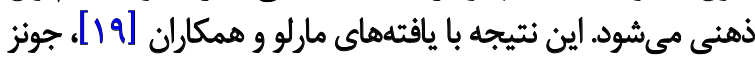

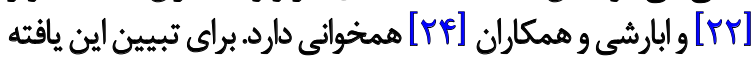

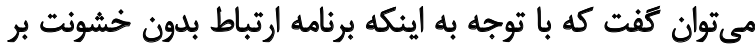

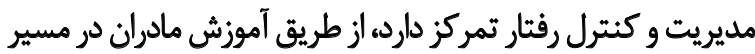

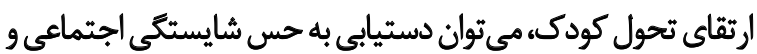

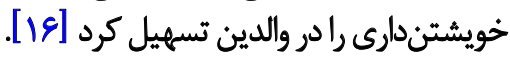

از سوى ديكر نتايج مطالعات انجامشده نشان مي دهد آموزش برنامه

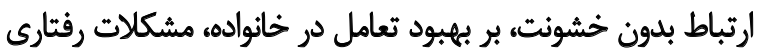

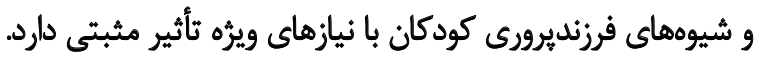

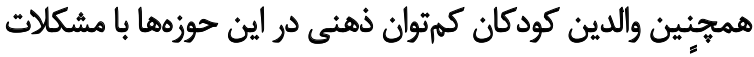

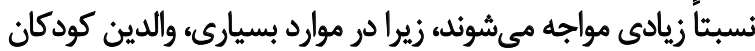

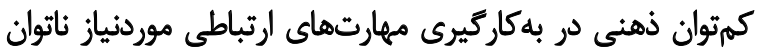

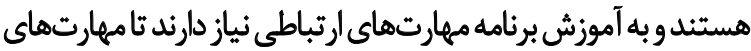

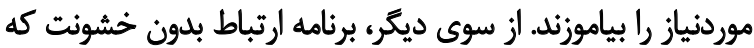

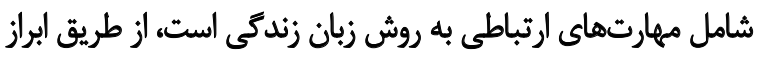

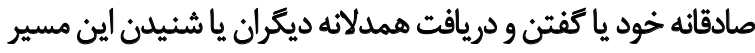

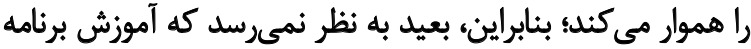

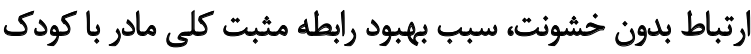
كمثتوان ذهنى شود.

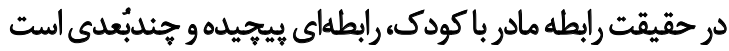

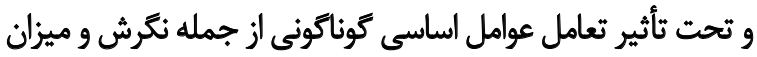

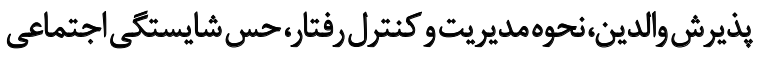

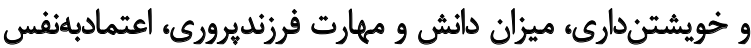

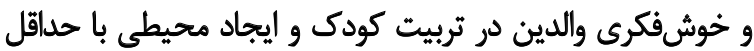

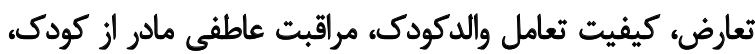

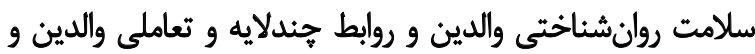

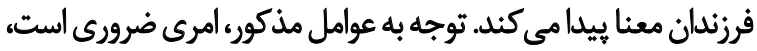

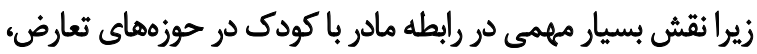

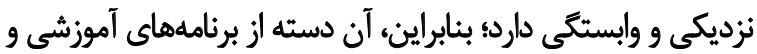

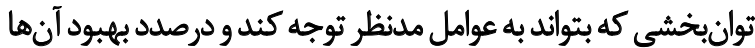

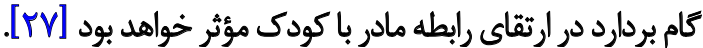

تتيجنيكيرى

به طور كلى يافتههاى اين يُروهش نشان داد آموزش برنامه ارتباط

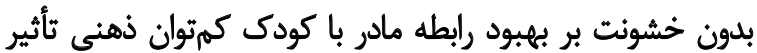

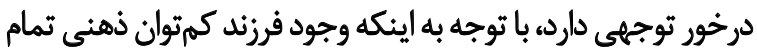

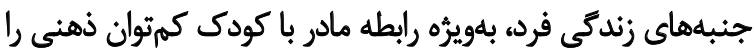

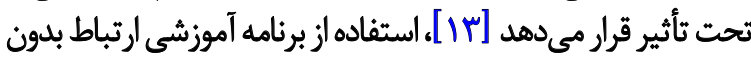

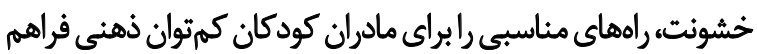

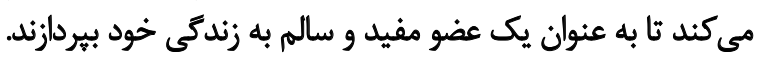

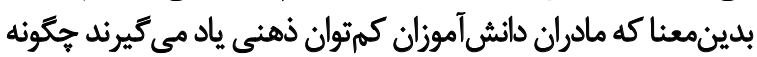

اين نتيجه با يافتههاى فوجيارا"|و وهمكاران مبنى بر بهببود اطمينان

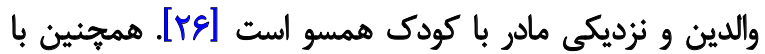

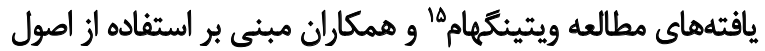

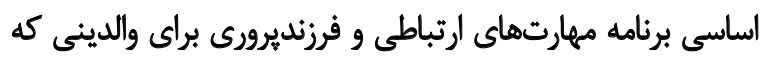

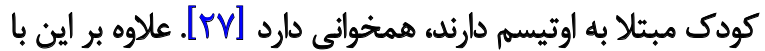

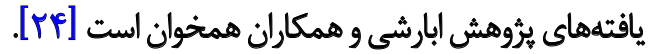

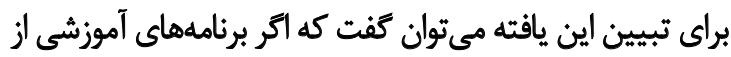

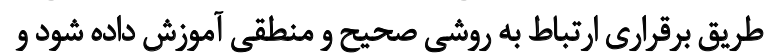

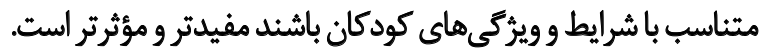

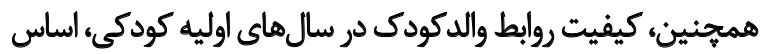

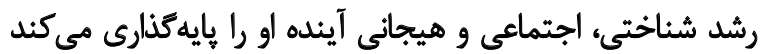

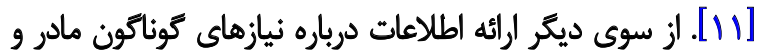

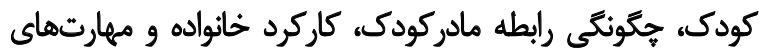

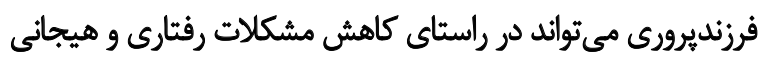

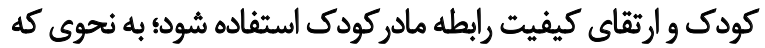

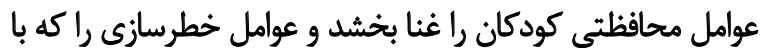

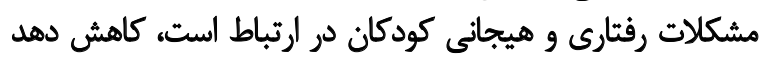

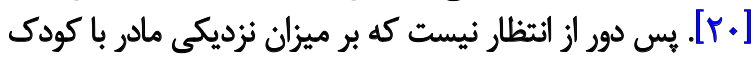
كمتوان ذهنى تأثير مطلوبى بكذارد.

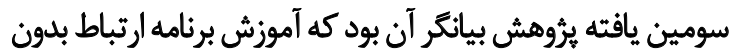

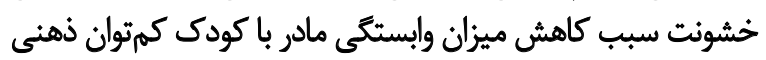

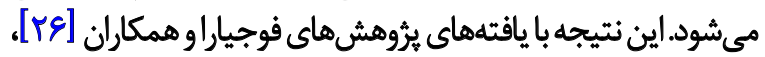

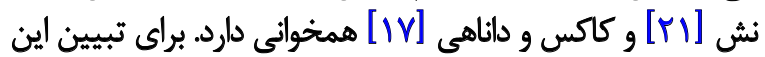

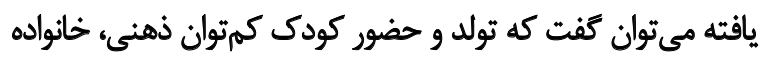

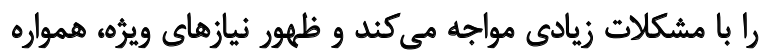

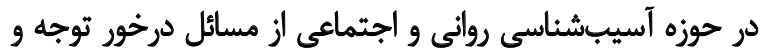

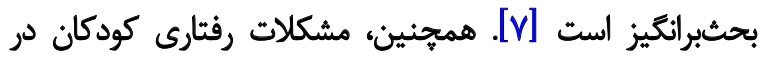

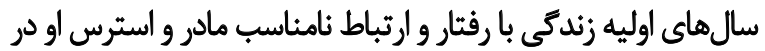

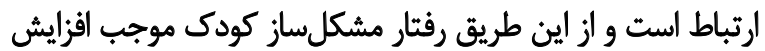

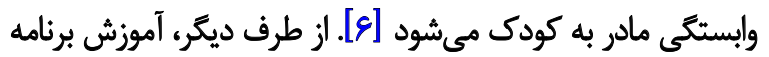

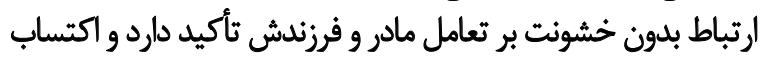

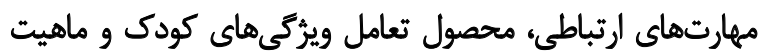

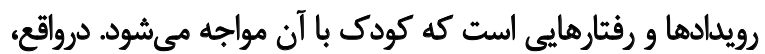

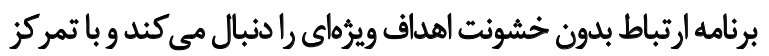

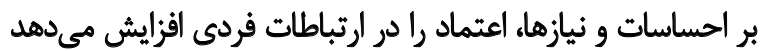

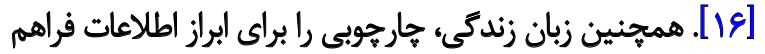

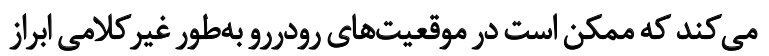

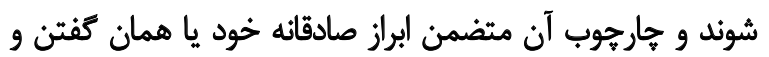

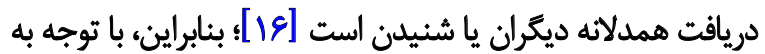

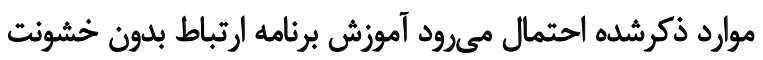

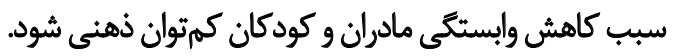

14. Fujiwara

15. Whittingham 
يويشبرد اهداف يُروهش در اختيار روانشناسان، آموزش و

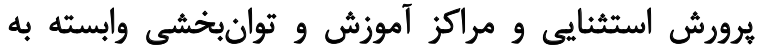
سازمان بهزيستى قرار كيرد.

$$
\text { ماهي مالب }
$$

اين يُوهش بركرفته از باياننامه كارشناسى ارشد نويسئده اول

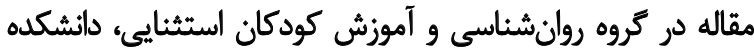
روانشناسى و علوم تربيتى، دانشكاه تهروان است

\section{مشاركتنويسندكان}

مشاركت نويسندكان به شح زير است: مفهومسازى: زهرا رضائى

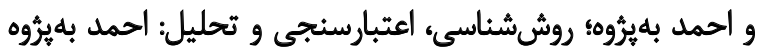

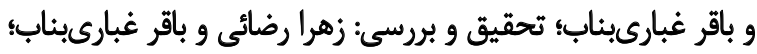
ويراستارى و نهايىسازي نوشته: زهرا رضائى.

$$
\text { تعارض مناقع }
$$

بنابر اظهار نويسندكان، اين مقاله تعارض منافع ندارد.

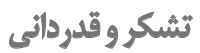

از مديريت محترم مركز آموزشى و توانبخشى كودكان كمتروان

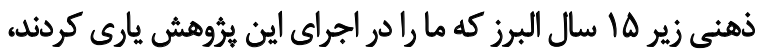

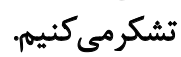

تصميم بكيرند، تفكر خلاق و انتقادى داشته باشند، جكَّنه احساس

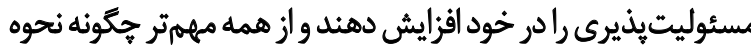

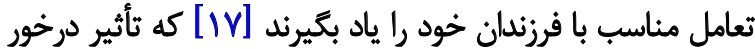

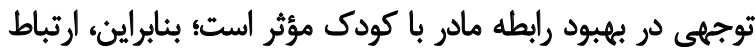

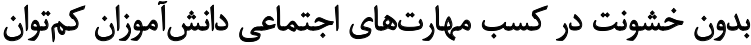

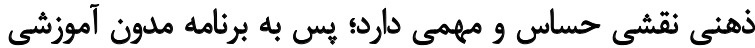

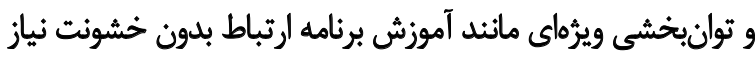

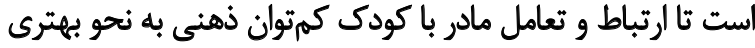

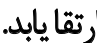

اين يثروهش با محدوديثهايى مواجه بوده است. با توجه به اينكه

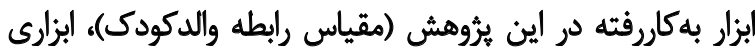

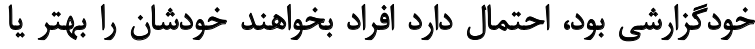

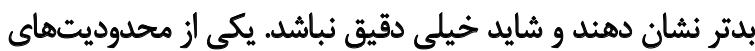

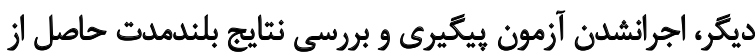

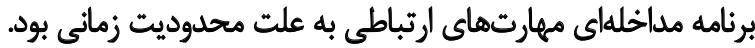

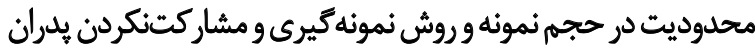

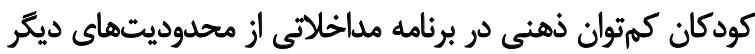

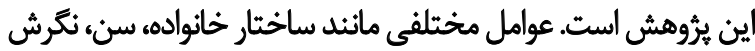

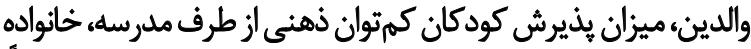

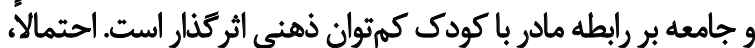

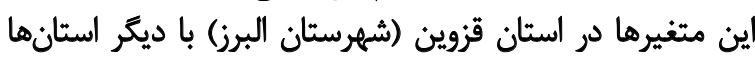
متفاوت است كه بايد در تعميم نثايج احتياط شودي

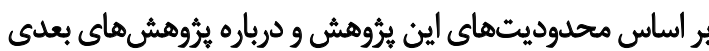

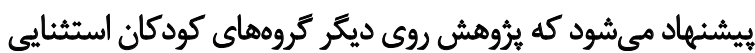

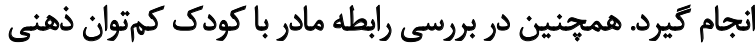

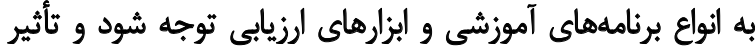

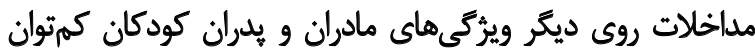

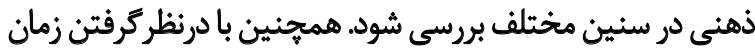

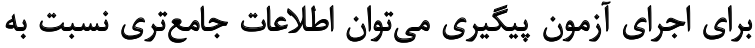

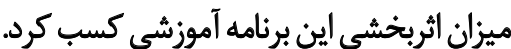

مالاحظاث اخلاقى

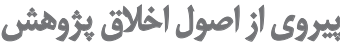

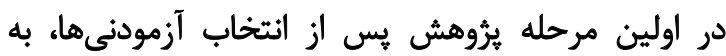

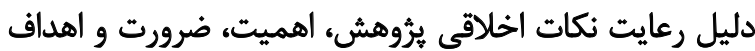

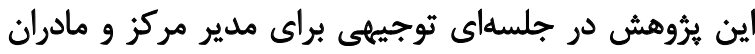

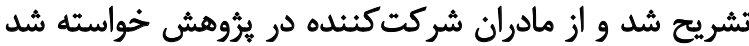

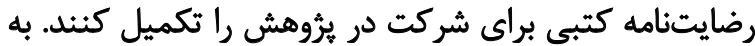

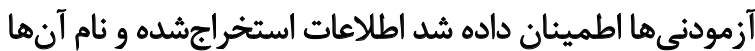

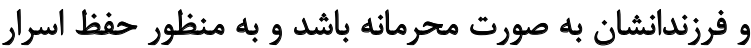

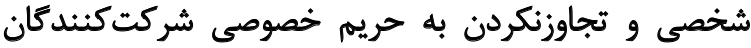

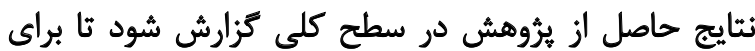




\section{References}

[1] Hallahan DP, Kauffman JM, Pullen PC. Exceptional learners: an introduction to special education. $13^{\text {th }}$ Edition. London: Pearson Education; 2015.

[2] Afrooz GA. [Introduction on the psychology and exceptional children education (Persian)]. 28 ${ }^{\text {th }}$ Edition. Tehran: Tehran University Publications; 2011.

[3] Jalil-Abkenar SS, Movallali G, Adibsereshki N, Ashoori M. [Investigation of the effectiveness social competence instruction on the adaptation behavior in boy students with intellectual disability (Persian)]. Archives of Rehabilitation. 2012; 12(4):57-67.

[4] Jalil-Abkenar SS, Ashoori M, Pourmohamadreza Tajrishi M. [The effectiveness social competence instruction on the adaptation behaviour in male students with intellectual disability (Persian)]. Archives of Rehabilitation. 2013; 13(5):104-13.

[5] Van Bysterveldt AK, Westerveld MF, Gillon G, Foster-Cohen S. Personal narrative skills of school-aged children with Down syndrome. International Journal of Language \& Communication Disorders. 2012; 47(1):95-105. [DOI:10.1111/j.1460-6984.2011.00085.x]

[6] Pourmohamadreza-Tajrishi M, Ashouri M, Afrooz GA, Arjmandnia AA, Ghobari-Bonab B. [The Effectiveness of positive parenting program (Triple-P) training on interaction of mother-child with intellectual disability (Persian)]. Archives of Rehabilitation. 2015; 16(2):128-37.

[7] Behroz-Sarcheshmeh S, Karimi M, Mahmoudi F, Shaghaghi P, JalilAbkenar SS. Effect of training of life skills on social skills of high school students with intellectual disabilities. Journal of Practice in Clinical Psychology. 2017; 5(3):177-86. [DOI:10.18869/acadpub. jpcp.5.3.177]

[8] Kandel I, Merrick J. Factors affecting placement of a child with intellectual disability. The Scientific World Journal. 2005; 5:370-6. [DOI:10.1100/tsw.2005.48] [PMID] [PMCID]

[9] Jalil-Abkenar SS, Ashoori M, Afrooz GHA. [The effect of social behaviors training on improvement of the social skills of adolescents with intellectual disability (Persian)]. Archives of Rehabilitation. 2013; 14(3):31-40.

[10] Cartwright-Hatton S, McNally D, White C, Verduyn C. Parent skill training: An effective intervention for internalizing symptoms in younger children. Journal of Child and Adolescent Psychiatric Nursing. 2005; 18(2):45-52. [DOI:10.1111/j.17446171.2005.00014.x] [PMID]

[11] Mantymaa M. Early mother-infant interaction. [MD. thesis]. Tampere: Tampere University; 2006.

[12] Bahrami B, Dolatshahi B, Pourshahbaz A, Mohammadkhani P. Parenting style and emotion regulation in mothers of preschool children. Journal of Practice in Clinical Psychology. 2018; 6(1):3-8. [DOI:10.29252/nirp.jpcp.6.1.3]

[13] Kirk S, Gallagher G, Coleman MR. Educating exceptional children. $14^{\text {th }}$ Edition. Boston, Massachusetts: Cengage Learning; 2015.

[14] Barlow J, Parsones J, Stewart-Brown S. Preventing emotional and behavioural problems: The effectiveness of parenting programmes with children less than 3 years of age. Child Care Health and Development. 2003; 31(1):33-42. [DOI:10.1111/j.13652214.2005.00447.x]

[15] Karney BR, Bradbury TN. Attributions in marriage: State or trait? A growth curve analysis. Journal of Personality and Social Psychology. 2000; 78(2):295-309. [DOI:10.1037/0022-3514.78.2.295]

[16] Rosenberg MB. Nonviolent communication: The language of compassion. $2^{\text {th }}$ Edition. Encinitas, California: PuddleDancer Press; 2003.

[17] Cox E, Dannahy P. The value of openness in e-relationships: using Nonviolent Communication to guide online coaching and mentoring. International Journal of Evidence Based Coaching and Mentoring. 2005; 3(1):39-51.

[18] Juncadella CM. What is the impact of the application of the nonviolent communication model on the development of empathy? [MSc. thesis]. Sheffield: University of Sheffield; 2013

[19] Marlow E, Nyamathi A, Grajeda WT, Bailey N, Weber A, Younger J. Nonviolent communication training and empathy in male parolees. Journal of Correcttonal Health Care. 2012; 18(1):8-19. [DOI:10.1177/1078345811420979] [PMID]

[20] F Branscomb J. Summative evaluation of a workshop in collaborative communication [MSc. thesis]. Atlanta: University of Emory 2011.

[21] Nash AN. Case study of Tekoa Institute: Illustration of nonviolent communication training's effect on conflict resolution [MSc. thesis]. Charlottesville: University of Virginia; 2007.

[22] Jones R. Understanding the nature of empathy: A personal perspective [MA. thesis]. London: University of East London; 2005

[23] Mohammadi M, Dowran B, Rabiei M, Salimi SH. [Construction and validation of an instrument for measuring the nonviolent communication (Persian)]. Journal of Police Medicine. 2015; $4(3): 161-70$

[24] Abarashi Z, Tahmasian K, Mazaheri MA, Panaghi L. [The impact of psychosocial child development training program, done through improvement of mother-child interaction, on parental self-efficacy and relationship between mother and child under three (Persian)]. Journal of Research in Psychological Health. 2009; 3(3):49-57.

[25] Gall M, Borg W, Gall j. Quantitative and qualitative methods of research in psychology and educational science [Nasr A, Arizi $\mathrm{H}$ Abolghasemi M, Pakseresht MJ, Kiamanesh A, Bagheri Kh, et al. Persian translator]. $1^{\text {st }}$ edition. Tehran: Samt; 2003.

[26] Fujiwara T, Kato N, Matthew R, Sanders MR. Effectiveness of group positive parenting program (triple $p$ ) in changing child behavior, parenting style, and parental adjustment: An intervention study in Japan. Journal of Child and Family Studies. 2011 20(6):804-13. [DOI:10.1007/s10826-011-9448-1]

[27] Whittingham K, Sofronoff K, Sheffield J, Sanders MR. Stepping stones Triple P: An RCT of a parenting program with parents of a child diagnosed with an Autism spectrum disorder. Journal of Abnormal Child Psychology. 2009; 37(4):469-80. [DOI:10.1007/ s10802-008-9285-x] [PMID] 